INTERNATIONAL JOURNAL OF RESEARCHES IN BIOSCIENCES, AGRICULTURE AND TECHNOLOGY (C) VISHWASHANTI MULTIPURPOSE SOCIETY (Global Peace Multipurpose Society) R. No. MH-659/13(N)

\title{
ANTIMICROBIAL PROPERTIES OF CALCIUM CHLORIDE LOADED POLYANILINE
}

\section{Sanjay Wagh}

Department of Chemistry, Shri Shivaji Art, Commerce and Science College, Akot, Dist. Akola Maharashtra

\begin{abstract}
:
In situ polymerised polyaniline (PANI) with calcium chloride produced by chemical method and tested fortheir antibacterial activity with respect to Escherichia coli. PANI with various concentration of calcium chloride showed a significant antibacterial effect against bacteria strains whilethe efficacy of neat PANI base was only marginal. After the calcium chloride impreganation, the PANI base exhibited different levels of antibacterial effect depending on the type of the bacterial strain. The results show that calcium chloride impregenation on PANI can be a suitable method for the preparation of PANI base material with improved antibacterial properties.
\end{abstract}

\section{Introduction:}

Outbreaks of food borne illness associated with consuming raw vegetables occur more frequently in recent years. Fresh-cut vegetables are highly susceptible to microbial contamination because of microbial cross-contamination through the shredders and slicers and the exposure of inner tissues to microbial attachment and growth after cutting. The pathogenic bacteria of the most concern in fresh vegetables include Escherichia coli O157:H7, Listeria monocytogenes, and Salmonella Typhimurium. Chemical agents such as sodium hypochlorite, chlorine dioxide, sodium bisulfite, sulfur dioxide, organic acids, calcium chloride, trisodium phosphate, ozone, and cetyl pyridinium chloride have been studied as potential disinfectants.

Besides all its advantages, application of polymers in medicine brings also a problem related to the occurrence of nosocomial infections. Therefore, a considerable effort has been exerted to develop polymers or composites with efficient antibacterial properties. In addition to polymer materials which possess an intrinsic antibacterial activity, these properties can be also achieved through coating or adsorption of an antibacterial agent on to the polymer surface; immobilisation of an antibacterial agent in the polymer via ionic or covalent bonding or by direct incorporation of an antibacterial agent in to the polymer during its synthesis $1-5$. Recently published studies indicate that among the polymers inherently showing antibacterial properties are also conducting polymers such as polyaniline (PANI)6-8, which has been the subject of considerable attention due to its potential in biomedical and other promising applications.Its efficacy against gram- positive and gram-negative bacteria and against fungi was first reported by Seshadri and $B$ hat ${ }^{9}$. . Seshadri and Bhat (2005) prepared cotton fabrics coated with an insitu polymerised PANI salt. They observed significant reduction of the colony forming units(CFU) of gram-positive Staphylococcus aureus (S.aureus,95\%), gram-negative Escherichia coli (E.coli,85\%)and Candida albicans fungi $(92 \%)$, which was explained by the activity of ions contained in PANI against the bacterial cell-wall. The following study reported total reduction of E.coli and S.aureus after $24 \mathrm{~h}$ of incubation on composite PANI films. In this case, possible explanation of the observed antibacterial effect was based on the FTIR measurements revealing the possibility of the change in molecular structure of the PANI composite after its interaction with the bacterial species. These papers offered also two different explanations of the mechanism of the PANI antibacterial effect, namely possible reaction of acidic dopants on the polymer chains with the bacteria and electrostatic adherence between the PANI macromolecules and the bacteria. Antibacterial properties of functionalised and standard PANIs were subject of interest in the thorough work. Though all tested substances showed antibacterial activity, functionalised polymers were more efficient compared to the standard ones. Not only the PANI polymer alone but also its acetone extracted oligomers were reported to possess antibacterial properties. Also Humpo-liceketal. (2012) reported a notable cytotoxicity of the PANI emerlaldine salt on human cells. Though the last mentioned study was conducted using eukaryotic, not bacterial cells, it also confirms the negative influence of PANI on cellular viability.

In the present paper we prepared a material containing polyaniline and various conctration of calcium chloride and its microbial study against E. Coli were tested

\section{Materials and Methods:}

Aniline monomer was purified by distillation before use. Ammonium persulfate, and other chemicals were used as received.

Polymerization: $0.2 \mathrm{M}$ aniline and specific molar concentrations of calcium chloride were mixed with stirring at room temperature for $30 \mathrm{~min}$. The stirring was then stopped, $50 \mathrm{ml}$ aqueous solution of $0.2 \mathrm{M}$ APS was added and the reaction was left for $12 \mathrm{hrs}$. The resulting PANI precipitate was washed with deionized water, methanol and ether several times. Finally the product was dried in vacuum at $80^{\circ} \mathrm{C}$ temperature for $24 \mathrm{hrs}$.

\section{Antibacterial Study:}

Prior to testing, the samples were disinfected by an exposure to an UV-radiation source $(258 \mathrm{~nm})$ emitted from a low-pressure $\mathrm{Hg}$ lamp UV-C Long Life 30W/G30TB, Phillips, The Netherlands).Polyaniline is stable under such treatment. As model microorganisms, the gramnegative E.coli strains were used. The test was performed according to ISO22196 with a modification. Nutrient broth with $1 \%$ peptone (M244) and nutrient agar No. 2(M1269) were used in the test (HiMedia Laboratories, India).

\section{Results and Discussion:}

Although PANI is considered as a promising conducting polymer for the application 
in biomedicine or more generally in biotechnology, only a few studies dealing with the antibacterial properties of this polymer have been published. Moreover, the majority of the studies is focused on the conducting PANI salt and only limited attention has been devoted to non-conducting PANI base. The published papers dealing with antibacterial activity of PANI and PANI based composites can be, for the purpose of the present study, divided into two groups: those concerning the activity of bare PANI and those concerning the properties of PANI containing calcium chloride. In the current study, calcium chloride are impregranated on the PANI surface by the immersion of naked PANI in a calcium chloride solution. The Electric conductivity behavior of calcium chloride impregranted PANI is shown in figure 1.

The results shows that, as the concentration was increases the electrical conductivity was increases up to the concentration of $0.4 \mathrm{~mol}$. Further increase in the concnetraton no change of electrical conductivity observed.

The key problem in the evaluation of the studies dealing with the antibacterial effect of PANI combined with calcium chloride is their inconsistency in terms of different methods of PANI preparation, results evaluation or the lack of information about the concentration and form of Ag. A pioneering study published by Prabhakar et $\mathrm{al}^{10}$ presented the reduction of biofilm formation (P. aeruginosa and $B$. subtilis) on polyurethane coated with a PANI-Ag nanoparticle composite. Tamboli et $\mathrm{al}^{11}$ found that in situ polymerised powder of PANIAg possesses antibacterial activity against B. subtilis superior to that of $\mathrm{Ag}$ nanoparticles as such. Using the disc diffusion method, which cannot be directly correlated with our test procedure, the minimum bactericidal concentration of PANI-calcium chloride was determined to be 68 $\mu \mathrm{g}$ mL-1. An improvement of the antibacterial activity of PANI after the calcium chloride impregranation onto the polymer surface was observed also in the current work. The results were represented in table 1.

In conclusion the PANI -calcium chloride material prepared by chemical method has a potential materials towards $\mathrm{E}$. Coli and will be a material for the various biomadeical applications.

\begin{tabular}{|l|c|}
\hline PANI type & $\begin{array}{l}\text { Antibacterial } \\
\text { activity(CFU) }\end{array}$ \\
\hline Pure PANI & 20 \\
\hline Pure PANI+0.1 CaCl 2 & 10 \\
\hline Pure PANI+ $0.2 \mathrm{CaCl}_{2}$ & 6 \\
\hline Pure PANI+0.3 CaCl 2 & 0 \\
\hline Pure PANI+0.4 CaCl 2 & 0 \\
\hline Pure PANI+0.5 CaCl 2 & 0 \\
\hline Pure PANI+0.6 CaCl 2 & 0 \\
\hline Pure PANI+0.7 CaCl 2 & 0 \\
\hline Pure PANI+0.8 CaCl 2 & 0 \\
\hline Pure PANI+ $0.9 \mathrm{CaCl}_{2}$ & 0 \\
\hline Pure PANI+ $1.0 \mathrm{CaCl}_{2}$ & 0 \\
\hline
\end{tabular}

Table.1- Antibacterial properties of PANI-calcium chloride material (CFU: Colony

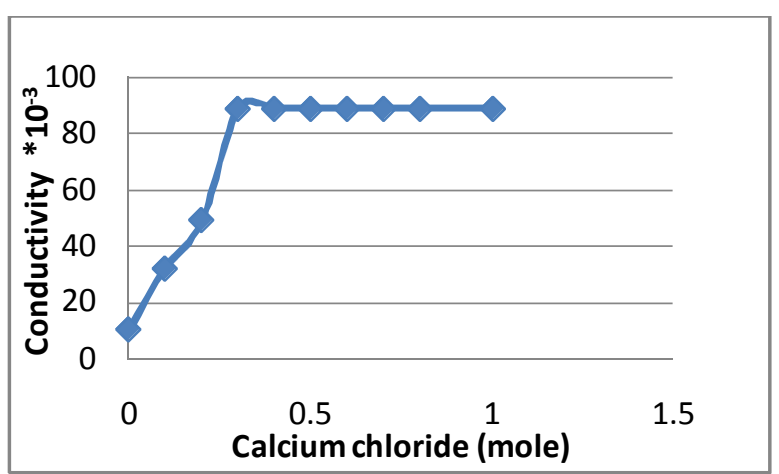

Figure 1: Effect of Calcium chloride concentration on electrical conductivity of PANI Forming Units)

\section{References:}

1. Bílek, F., Kř̌ǐzová, T., \& Lehocký, M. (2011). Preparation of active antibacterial LDPE surface through multistep physicochemical approach: I. Allylamine grafting, attachment of antibacterial agent and antibacterial activity assessment. Colloids and Surfaces B: Biointerfaces, 88, 440-447.

2. Blinova, N. V., Sapurina, I., Klimovi'c, J., \& Stejskal, J. (2005). The chemical and colloidal stability of polyaniline dispersions. Polymer Degradation and Stability, 88, 428-434.

3. Gizdavic-Nikolaidis, M. R., Bennett, J., Zujovic, Z., Swift, S. Bowmaker, G. A. (2012). Characterization and antimicrobial efficacy of acetone extracted aniline oligomers. Synthetic Metals, 162, 1114-1119.

4. Humpolicek, P., Kasparkova, V., Saha, P., \& Stejskal, J. (2012).Biocompatibility of polyaniline. Synthetic Metals, 162, 722-727.

$5 . \quad J i a$, Q., Shan, S., Jiang, L., Wang, Y., \& Li, D. (2012). Synergetic antimicrobial effects of polyaniline combined with silver nanoparticles. Journal of Applied Polymer Science, 125, 3560-3566.

6. Liang, X., Sun, M., Li, L., Qiao, R., Chen, K., Xiao, Q., \& Xu, F. (2012). Preparation and antibacterial activities of polyaniline/Cu0.05Zn 0.950 nanocomposites. Dalton Transactions, 41, 2804-2811.

$7 . \quad$ Nabi, S. A., Shahadat, M., Bushra, R., Oves, M., \& Ahmed, F. (2011). Synthesis and characterization of polyaniline $\operatorname{Zr}(\mathrm{IV})$ sulphosalicylate composite and its applications (1)electrical conductivity, and (2) antimicrobial activity studies. Chemical Engineering Journal, 173, 706-714.

8. Stejskal, J., \& Gilbert, R. G. (2002). Polyaniline. Preparation of a conducting polymer (IUPAC Technical Report).Pure and Applied Chemistry, $74,857-867$.

9. Seshadri, D. T., \& Bhat, N. V. (2005). Use of polyaniline as an antimicrobial agent in textiles. Indian Journal of Fibre \&Textile Research, 30, 204206.

10. Prabhakar, P. K., Raj, S., Anuradha, P. R., Sawant, S. N.,\& Doble, M. (2011). Biocompatibility studies on polyaniline and polyaniline-silver nanoparticle coated polyurethane composite. Colloids and Surfaces B: Biointerfaces, 86, 146-153.

11. Tamboli, M. S., Kulkarni, M. V., Patil, R. H., Gade, W. N., Navale, S. C., \& Kale, B. B. (2012). Nanowires of silver-polyaniline nanocomposite synthesized via in situ polymerization and its novel functionality as an antibacterial agent. Colloids and Surfaces B: Biointerfaces, 92, 35-41. 